\title{
Clinical study of Masquelet technique in the treatment of osteomyelitis and bone defect
}

\author{
Bikash Neupane $^{1 *}$, Zhao Meng ${ }^{1}$, Xu Sheng Kang1, Prabha Paudel², \\ Sagar Panthi ${ }^{3}$, Zhao Xing ${ }^{1}$, Zhang Jin Song ${ }^{1}$
}

\begin{abstract}
${ }^{1}$ Department of Orthopedics, Unit IV, Taihe Hospital, Hubei, China
${ }^{2}$ Department of Stastistics, Tribhuwan University, Nepal,

${ }^{3}$ Rapti Academy of Health Science (RAHS), Nepal
\end{abstract}

Received: 07 June 2021

Revised: 12 July 2021

Accepted: 13 July 2021

\section{*Correspondence:}

Dr. Bikash Neupane,

E-mail: neupanebikash072@gmail.com

Copyright: (c) the author(s), publisher and licensee Medip Academy. This is an open-access article distributed under the terms of the Creative Commons Attribution Non-Commercial License, which permits unrestricted non-commercial use, distribution, and reproduction in any medium, provided the original work is properly cited.

\begin{abstract}
Background: The induced membrane technique, introduced by Masquelet in 1986 called Masquelet technique is universally preferred methods of treatment in bone defect either of any cause. Consists of two principle steps: first radical debridement and filling defect with polymethylmethacrylate (PMMA) spacer, this allows the formation of induction membrane. Secondly bone cement is removed and defect is filled with bone graft and stabilized with definitive fixation.

Methods: This prospective observational study was carried out in the department of orthopedic surgery, Taihe Hospital affiliated to Hubei University of Medicine, Shiyan Hubei China from July 2018 to November 2019.

Results: Total 32 patients observed and recorded for the analysis. The mean age 38.28 \pm 11.211 years. $20(62.5 \%)$ male and $12(37.5 \%)$ female, $13(40.6 \%)$ had right, and $19(59.4 \%)$ had left side injury. Tibia has the highest involvement 16 $(50 \%)$, femur $10(31.3 \%)$, calcaneus $3(9.4 \%)$ radius, cuboid and ulna $1(3.1 \%)$ each. For cause of defect osteomyelitis is found to have highest frequency of 11 (34.4\%). The size of defect ranges from 3 to $20 \mathrm{~cm}$ with mean defect $(6.91 \pm 4.489 \mathrm{~cm})$. Duration of bone cement ranges from $4-20$ weeks with mean of $8.75 \pm 3.379$ weeks. The union time ranges from 4-14 months. With mean of $8.31 \pm 2.17$ months. $18(56.3 \%)$ have excellent results, $13(40.6 \%)$ have good results, and 1 patient $(3.1 \%)$ have satisfactory results.

Conclusions: This study concludes that Masquelet technique as being the more appropriate, reliable and is a noble technique in the reconstruction of bone defect either of any cause with good functional result.
\end{abstract}

Keywords: Masquelet technique, Bone defects, Induced membrane, Reconstruction

\section{INTRODUCTION}

Segmental bone defects due to traumatic injuries are complex conditions with morbidity.in the past because of complexity in treating such defects amputation was preferring methods of treatment, around the era of the Second World War, the cancellous bone grafting method was developed. ${ }^{1}$ Reconstruction of bone defects in diaphysis is still a major challenge, several methods are used with the common goal of regenerating bone loss and restoring function. ${ }^{2}$ Bone defects are widespread with osteomyelitis and traumatic segmental bone loos are common cause The treatment of these injuries remains controversial, particularly for the critical-sized defects, $(6.0-7.0 \mathrm{~cm})$ non-critical defects can be cured without reconstruction and secondary surgery from cancellous bone grafting, defects of up to $4.0 \mathrm{~cm}$ could be successfully managed. ${ }^{3}$ Large defects need more complicated alternatives. ${ }^{4}$ Optimal patient characteristics for the reconstruction of segmental bone defects include a healthy 
and well patient adequate soft-tissue covering, better nutritional status, no use of tobacco, absence of disease. ${ }^{5}$ The induced membrane technique, introduced by Masquelet in 1986, was frequently studied in surgical literature until recently, when the 2010 annual convention symposium of the French Society of Orthopedic Chirurgy and Traumatology (SoFCOT) reviewed a wide series of cases using this technique. ${ }^{6}$ This technique consists of two principle stage, debridement till paprika sign and filling defect with cement and antibiotics is the first phase, the second phase consists of removal of cement and insertion of bone graft with definitive fixation and post-operative wound care. ${ }^{7}$ By this process, it is possible to fill the defect from a smaller size up to $25 \mathrm{~cm}$ or even a larger defect. The membrane formed during the first stage is built around the bone cement and has biological properties that prevent the resorption of the graft and help to heal properly. This membrane also has a capillary and osteogenic character that secretes growth factors. ${ }^{8,9}$ The induced membranes were thicker than the periosteum, at 2 weeks the membranes induced were the thickest and thickness decreased over time. ${ }^{10}$ Soft tissue coverage is essential after fixation and bone grafting and the limb are immobilized, Post-operative radiography and routine follow-up should be done. ${ }^{11}$ This approach can now be used to treat congenital defects, including congenital pseudo arthrosis, to replace long and difficult conventional treatment. A longer follow-up would be required to evaluate and verify the effectiveness of this technique of pediatric reconstruction. ${ }^{12}$

\section{Objectives}

General objectives were to access the clinical effects and functional outcomes in patients who underwent surgery for the bone defect of various cause by the use of Masquelet technique.

Specific objectives were to access- the size of defect, time of final surgery, blood loss, duration of bone cement, union time, cause of defect, side of injury, name and number of bones involved, indication for surgery, modes of definitive fixation, limb length discrepancy, complications, donor site pain.

\section{METHODS}

This prospective study was carried out in the department of orthopedic surgery, Taihe Hospital affiliated to Hubei University of Medicine. Shiyan, Hubei, China from July 2018 to November 2019. A total of 32 patients were enrolled in this study. Data were retrieved from patient's history and operative notes. Statistical analysis was done using the statistical package for the social sciences (SPSS) 25.0 statistical software, Microsoft word and excel version 2016. This study was a descriptive observational study.

Table 1: Inclusion and exclusion criteria.

\begin{tabular}{|ll|}
\hline Inclusion criteria & Exclusion criteria \\
\hline Age -more than 3 years to 70 years; sufficient data in medical record file & $\begin{array}{l}\text { Age less than } 3 \text { more than } 70 \text { patients } \\
\text { had associated injury }\end{array}$ \\
\hline No preoperative neurovascular injury & Congenital bone defect \\
\hline No congenital bone defect & Underlying neuromuscular disorder \\
\hline Adequate available radiographic documentation with regular follow up & Metabolic bone disorder \\
\hline Grade I and II and III open fracture & Life-threatening or comorbidities \\
\hline Bone defect by osteomyelitis & Patient loosing follow up \\
\hline Bone defect by trauma & \\
\hline Pathological fracture & \\
\hline RTA patients with segmental bone loss & \\
\hline
\end{tabular}

\section{RESULTS}

The mean age $( \pm \mathrm{SD})$ was $38.28( \pm 11.211)$ years. Among which $20(92.5 \%)$ were male and $12(37.5 \%)$ were female. the duration of surgery ranges from 85 minutes to 380 minutes, with an average of 160.69 minutes, $( \pm 58.651)$. for the cause of defects osteomyelitis has the highest frequency with $11(34.4 \%)$ fall injury $9(28.1 \%)$ accident $7(21.9 \%)$ other forms of trauma with $5(15.6 \%)$. tibia being the highest number $16(50.0 \%)$ in bone involved, femur $10(31.3 \%)$, calcaneus $3(9.4 \%)$, radius, cuboid and ulna have same frequency of $1(3.1 \%)$ each respectively.so we can state that this technique is mostly used on treating long bone defects of any cause in lower extremity for the most part of tibia. all the patient underwent bone graft with various modes of definitive fixation. $23(71.9 \%)$ had bone graft and plate fixation. $4(12.5 \%)$ bone graft with IM nail. $3(9.4 \%)$ bone graft, k-wire and plate fixation. $2(6.3 \%)$ bone graft, plate, and superficial thickness skin graft. where $22(68.8 \%)$ were operated because of chronic osteomyelitis, $7(21.9 \%)$ have tumor. $1(3.1 \%)$ is found to have segmental bone loss. And $2(6.3 \%)$ have an indication of osteomyelitis with non-union. the duration of bone cement ranges from 4 weeks to 20 weeks, with an average of 8.75 weeks ( \pm SD 3.379), where a maximum number of patients who had bone cement were noted from 8 to 11 weeks. Mean defect was $6.91 \mathrm{~cm} \pm$ SD 4.489. The mean $( \pm$ SD) of hospital stay time was 21.78 days $( \pm 9.328)$ days. All patients were regularly followed up at $6^{\text {th }}$ and $8^{\text {th }}$ week and 3 months. 6 months and 12 months, the union time ranges from 4 to 14 months. With an average mean of 8.31 months, with $( \pm \mathrm{SD})$ of $( \pm 2.17)$ months. $18(56.3 \%)$ have 
excellent results, $13(40.6 \%)$ have god results, and 1 $(3.1 \%)$ have satisfactory results.

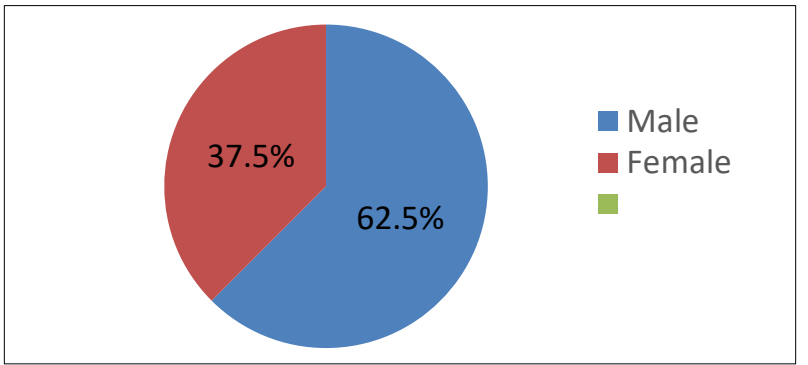

Figure 1: Male female percentage.

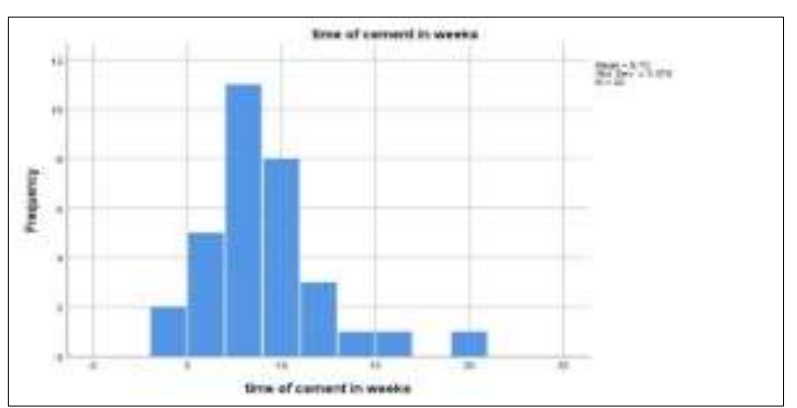

Figure 2: Duration of cement.



Figure 3: Side of injury (left $>$ right).

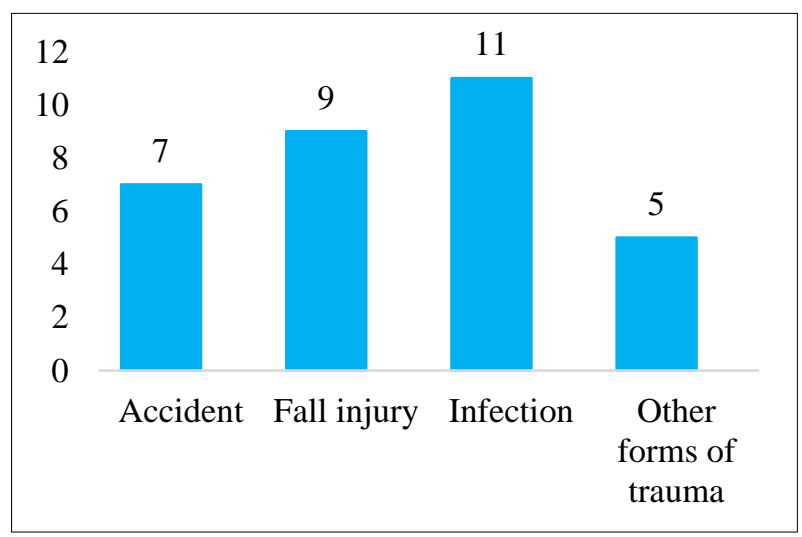

Figure 4: Cause of defects.

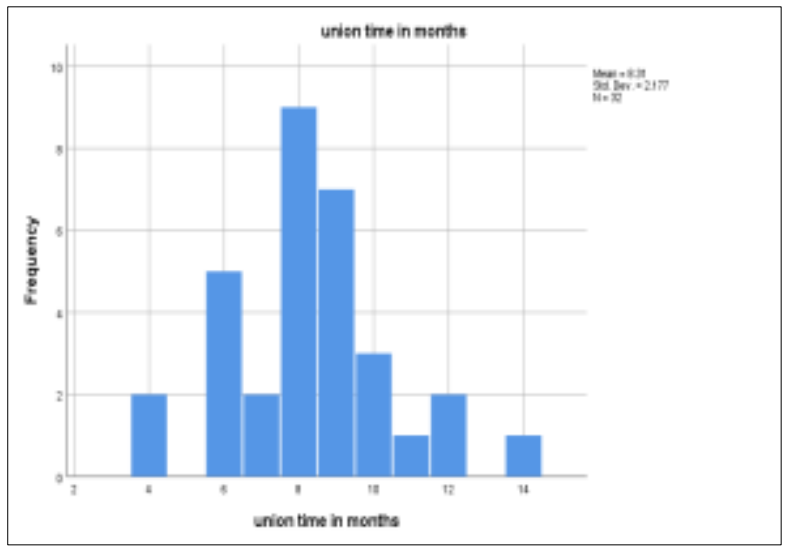

Figure 5: Union times.

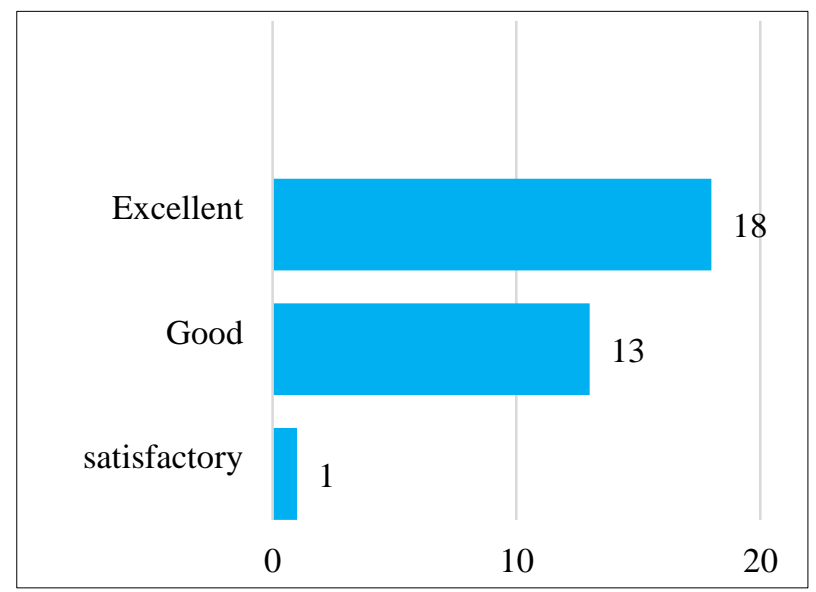

Figure 6: Final outcomes
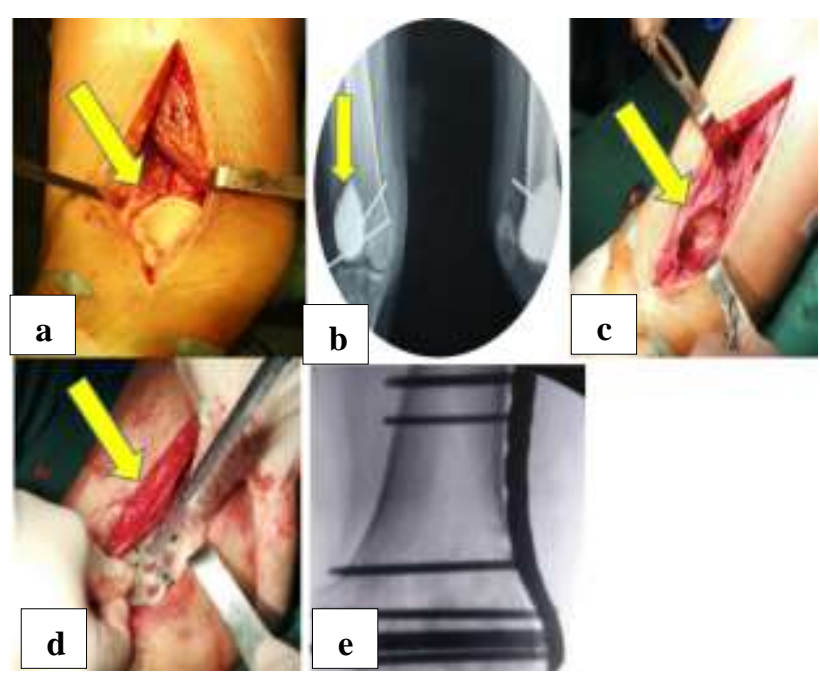

Figure 7: Right distal femur with bone defect and treated with masquelet technique (a) right femur showing defect filled with cement, (b) x-ray showing defect filled with cement and k-wire fixation, (c) defect after removal of cement with clear membrane, (d) defect filled with bone graft and plate fixation, and (e) $x$-ray image after bone graft and plate fixation. 

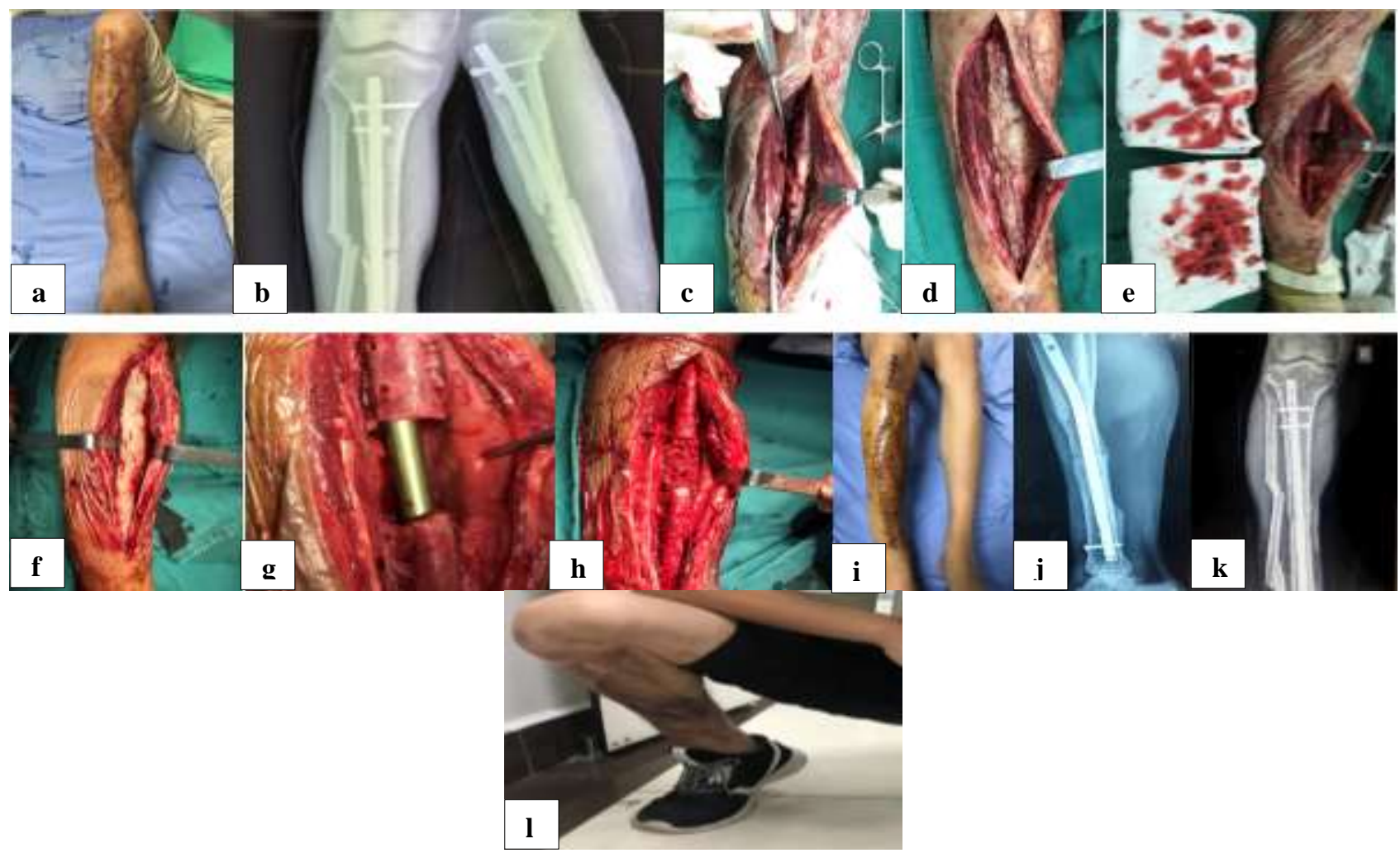

Figure 8: Right tibia infected nonunion treated with masquelet technique (a) right leg with unhealthy scar and sign of infection, (b) initial $x$ ray of right leg showing infected nonunion, (c) and (d) during surgery showing infected bone, (e) after debridement showing fresh ends of bone (paprika sign), (f) filling defect with antibiotics mixed bone cement, (g) removing of bone cement and showing healthy membrane, (h) filling defect with bone graft, (i) postoperative wound, (j) and (k) 10 months' post-operative $x$ ray image showing healing of bone, and (l) right leg with adequate knee flexion.

Table 2: Average age, size of defect, timing of final surgery; duration of cement, blood loss and union time.

\begin{tabular}{|lllll|}
\hline Variable & Mean & Standard deviation & Minimum & Maximum \\
\hline Age & 38.28 & 11.211 & 5 & 61 \\
\hline Defect size (in cm) & 6.91 & 4.489 & 3 & 20 \\
\hline Final surgery time (in minute) & 160.69 & 58.651 & 85 & 380 \\
\hline Duration of cement (in a week) & 8.75 & 3.379 & 4 & 20 \\
\hline Blood loss (in ml) & 179.69 & 272.518 & 20 & 1300 \\
\hline Union time (in month) & 8.31 & 2.177 & 4 & 14 \\
\hline
\end{tabular}

Table 3: Different variables (cause of defects, fracture type, side of injury, bone involved, definitive fixation, indication of operation, LLD, complications, donor site pain) with their frequency and percentage.

\begin{tabular}{|llll|}
\hline Variable & Characteristics & Frequency & Percent \\
\cline { 2 - 4 } Cause of defect & Accident & 7 & 21.9 \\
\cline { 2 - 4 } & Fall injury & 9 & 28.1 \\
\cline { 2 - 4 } & Infection & 11 & 34.4 \\
\cline { 2 - 4 } Fracture type & Other forms of trauma & 5 & 15.6 \\
\cline { 2 - 4 } & Open & 8 & 34.4 \\
\cline { 2 - 4 } & Closed & 6 & 25 \\
\cline { 2 - 4 } Side of injury & Pathological & 7 & 18.8 \\
\cline { 2 - 4 } & Fracture due to infection & 13 & 21.9 \\
\hline Bone involved & Right & 19 & 40.6 \\
\cline { 2 - 4 } & Left & 16.4 \\
\hline
\end{tabular}

Continued. 


\begin{tabular}{|c|c|c|c|}
\hline Variable & Characteristics & Frequency & Percent \\
\hline & Femur & 10 & 31.3 \\
\hline & Calcaneus & 3 & 9.4 \\
\hline & Radius & 1 & 3.1 \\
\hline & Cuboid & 1 & 3.1 \\
\hline & Ulna & 1 & 3.1 \\
\hline \multirow{4}{*}{ Definitive fixations } & Bone graft+plate & 23 & 71.9 \\
\hline & Bone graft+IM nail & 4 & 12.5 \\
\hline & Bone graft+k-wire+plate & 3 & 9.4 \\
\hline & Bone graft+plate+skin graft & 2 & 6.3 \\
\hline \multirow{4}{*}{ Indication of operation } & Osteomyelitis & 22 & 68.8 \\
\hline & Tumor & 7 & 21.9 \\
\hline & Segmental bone loss & 1 & 3.1 \\
\hline & Osteomyelitis with non-union & 2 & 6.3 \\
\hline \multirow{2}{*}{ Limb length discrepancy } & No & 28 & 87.5 \\
\hline & $2 \mathrm{~cm}$ & 4 & 12.5 \\
\hline \multirow{3}{*}{ Complication } & No complication & 27 & 84.4 \\
\hline & Joint contracture & 1 & 3.1 \\
\hline & Stiffness & 4 & 12.5 \\
\hline \multirow{2}{*}{ Donor site pain } & No pain & 28 & 87.5 \\
\hline & Pain & 4 & 12.6 \\
\hline
\end{tabular}

\section{DISCUSSION}

The purpose of this study is was to study the outcome of Masquelet technique in done defects due to various causes, Rigal and Merloz et al in 2011 found that this technique is mostly used in lower limbs for the most part of the tibia. ${ }^{13}$ We also have more number of patients with tibia involvement 50\%. Aparda and Bigorre et al in 2010, has done similar research in 12 patients where the frequency of male patients was more, our result also shows the highest frequency of male patients 20 (92.5\%) than females $12(37.5 \%) .{ }^{14}$ Similar to us, Wang et al have also found a number of male patients were high then females. ${ }^{15}$ In 2015 Marais et al have found out that joint contractures, ankle equinus, and knee flexion were complications after surgery, similar complication were noted in few patients on regular follow up 27 patients $(84.4 \%)$ have no any complication $4(12.5 \%)$ patient have joint stiffness, and 1 patient $(3.1 \%)$ have joint contracture. ${ }^{16}$ These 5 patients have adequate healing of bone but have been found neglecting the physiotherapy. Yeganeh et al in 2016 also found that this technique is used frequently in lower limbs. ${ }^{17}$ Our result also shows lower limb has the highest frequency (tibia $>$ femur). Marais et al also found the mean defect size of $7 \mathrm{~cm}$, which is almost equal to ours 6.91 $\mathrm{cm} .{ }^{16}$ Rigal et al found average union time was 14.9 months where, all patients were regularly followed up at $6^{\text {th }}$ and $8^{\text {th }}$ week and 3 months, 6 months and $12-15$ months, the union time ranges from 4 to 14 months. ${ }^{13}$ With an average mean of 8.31 months, with $( \pm \mathrm{SD})$ of $( \pm 2.17)$ months which shows our result is superior in comparison to them and where 4 patients $(12.5 \%)$ were noted to have limb length discrepancy of around $2 \mathrm{~cm}$. In March 2016, Xie et al published a paper showing details of evaluation or results in lower limb categorizing excellent, good fair and poor with certain variables. ${ }^{18}$ Based on these parameters we calculated our results. 18 (56.3\%) have excellent results, $13(40.6 \%)$ have good results, $1(3.1 \%)$ have satisfactory results. Yeganeh et al conducted research in 2016 among 21 patients one had to go amputation due to medical condition and on had a history of re infection. ${ }^{17}$ But none of our patients present with re-infection and none of them went amputation, our follow up timing was quite shorter of around one year to 16 months, where if we see on different research article patients were asked to follow up till 28 , to 30 months, so based on our research we have achieved $96 \%$ of positive and best results, remaining $4 \%$ also have satisfactory results. ${ }^{13-16}$ All the patient of able to return to their normal function. Wang et al in 2017 among 15 patients where two of them had a recurrent infection and need extra surgery but our patients did not need extra surgery. ${ }^{15}$ Qiu et al in 2017. ${ }^{19}$ Where they have classified two groups of a patient, bead group and spacer group, the good results of the patient among bead group was analyzed and concluded where the union time was around of 8.5 month which is almost equal to our union time 8.31 months. Thus in our study all patients were treated according to principle of Masquelet technique maximum number of patient had excellent and good results of $96 \%$ without re infection and neither of them went for amputation. Thus the induced membrane technique can be used to address and allow for early fracture healing in bigger defects. The Ilizarov method of bone transportation is the only method that comes closer, but it is time consuming and requires more experience. ${ }^{20}$

\section{CONCLUSION}

This study concludes that, though the reconstruction of bone defect is a really challenging problem, Masquelet technique is universally accepted novel and effective technique in treatment or reconstruction of bone defects 
either of any cause like. trauma, tumor, infection, segmental bone loss etc. this technique provides better results with minimal blood loss, shorter operative time, less complications, early healing with better functional outcomes. The results of this study suggest that Masquelet technique shows the potential of new bone formation in large bone defects of any cause with adequate and early healing.

Funding: No funding sources

Conflict of interest: None declared

Ethical approval: The study was approved by the institutional ethics committee

\section{REFERENCES}

1. Wong TM, Lau TW, Li X, Fang C, Yeung K, Leung F. Masquelet technique for the treatment of posttraumatic bone defects. Sci World J. 2014.

2. Giannoudis P V, Faour O, Goff T, Kanakaris N, Dimitriou R. Masquelet technique for the treatment of bone defects: Tips-tricks and future directions. Injury. 2011;42(6):591-8.

3. Schemitsch EH. Size Matters: Defining Critical in Bone Defect Size. J Orthop Trauma. 2017;31(10):202.

4. Motsitsi NS. Masquelet's Technique for Management of Long Bone Defects: From Experiment to Clinical Application. East Cent African J Surg. 2012;43-7.

5. Barlow BT, Smith W. Management of Segmental Abstract. J Am Acad Orthop Surg. 2015;23(3):14353.

6. Karger C, Kishi T, Schneider L, Fitoussi F, Masquelet AC. Treatment of posttraumatic bone defects by the induced membrane technique. Orthop Traumatol Surg Res. 2012;98(1):97-102.

7. Azi ML, Teixeira A de AA, Cotias RB, Joeris A, Kfuri M. Induced-Membrane Technique in the Management of Posttraumatic Bone Defects. JBJS Essent Surg Tech. 2019;9(2):22.

8. Pelissier P, Masquelet AC, Bareille R, Mathoulin Pelissier S, Amedee J. Induced membranes secrete growth factors including vascular and osteoinductive factors and could stimulate bone regeneration. J Orthop Res. 2004;22(1):73-9.

9. Lashin AM, Sc M, Mousa WF, Hosni MM. Induced Membrane (Masquelet) Technique for Treatment of Long Bone Defects. 2018;86(1):215-22.

10. Wang X, Wei F, Luo F, Huang K, Xie Z. Induction of granulation tissue for the secretion of growth factors and the promotion of bone defect repair. $\mathrm{J}$ Orthop Surg Res. 2015;10(1):4-11.

11. Mühlhäusser J, Winkler J, Babst R, Beeres FJP. Infected tibia defect fractures treated with the Masquelet technique. Med (United States). 2017;96(20):1-7.

12. Gouron R. Surgical technique and indications of the induced membrane procedure in children. Orthop Traumatol Surg Res. 2016;102(1):133-9.

13. Rigal S, Merloz P, Le Nen D, Mathevon H, Masquelet AC. Bone transport techniques in posttraumatic bone defects. Orthop Traumatol Surg Res. 2012;98(1):103-8.

14. Apard T, Bigorre N, Cronier P, Duteille F, Bizot P, Massin P. Two-stage reconstruction of posttraumatic segmental tibia bone loss with nailing. Orthop Traumatol Surg Res. 2010;96(5):549-53.

15. Wang X, Wang Z, Fu J, Huang K, Xie Z. Induced membrane technique for the treatment of chronic hematogenous tibia osteomyelitis. BMC Musculoskelet Disord. 2017;18(1):1-7.

16. Marais LC, Ferreira N. Bone transport through an induced membrane in the management of tibial bone defects resulting from chronic osteomyelitis. Strateg Trauma Limb Reconstr. 2015;10(1):27-33.

17. Yeganeh A, Mahmodi M, Farahini H, Moghtadaei M. Short-term Outcomes of Induced Membrane Technique in Treatment of Long Bone Defects in Iran. Med Arch (Sarajevo, Bosnia Herzegovina). 2016;70(4):284-7.

18. Wang X, Luo F, Huang K, Xie Z. Induced membrane technique for the treatment of bone, defects due to post-traumatic osteomyelitis. Bone Jt Res. 2016;5(3):101-5.

19. Qiu XS, Chen YX, Qi XY, Shi HF, Wang JF, Xiong J. Outcomes of cement beads and cement spacers in the treatment of bone defects associated with posttraumatic osteomyelitis. BMC Musculoskelet Disord. 2017;18(1):1-6.

20. Sivakumar R, Mohideen MG, Chidambaram M, Vinoth T, Singhi PK, Somashekar V. Management of Large Bone Defects in Diaphyseal Fractures by Induced Membrane Formation by Masquelet's Technique. J Orthop Case Rep. 2016;6(3):59-62.

Cite this article as: Neupane B, Meng Z, Kang XS, Paudel P, Panthi S, Xing Z, et al. Clinical study of Masquelet technique in the treatment of osteomyelitis and bone defect. Int J Res Orthop 2021;7:901-6. 